\title{
The influence of non-toxic concentrations of DDT and DDE on the old world vulture estrogen receptor alpha
}

\author{
Vinny Naidoo ${ }^{\mathrm{a}, *}$, Yoshinao Katsu ${ }^{\mathrm{b}, \mathrm{c}}$, Taisen Iguchi ${ }^{\mathrm{b}, \mathrm{c}}$ \\ a Department of Paraclinical Sciences, Faculty of Veterinary Science, University of Pretoria, Private Bag X04, Section of Pharmacology, Onderstepoort, 0110, South Africa \\ ${ }^{\mathrm{b}}$ Okazaki Institute for Integrative Bioscience, National Institute for Basic Biology, National Institutes of Natural Sciences, 5-1 Higashiyama, Myodaiji, Okazaki 444-8787, Japan \\ ${ }^{\mathrm{c}}$ Department of Basic Biology, The Graduate University for Advanced Studies (SOKENDAI), 5-1 Higashiyama, Myodaiji, Okazaki 444-8787, Japan
}

\section{A R T I C L E I N F O}

\section{Article history:}

Received 11 April 2008

Revised 28 July 2008

Accepted 14 August 2008

Available online $\mathrm{xxxx}$

\section{Keywords:}

DDT

DDE

Endocrine disruptor

Vulture

Organochlorine

Estrogen receptor

\begin{abstract}
A B S T R A C T
Seven of the nine vulture species in South Africa are listed as endangered on the International Union for the Conservation of Nature (IUCN) red list. From these, the Cape Griffon vulture (Gyps corprotheres) is the most endangered species in the region. Although inadequate nutritional support has been blamed on the constant decline in populations, the process of vulture restaurants has failed to improve the population status over the last twenty years. One possible reason for the decline may be an underlying reproductive disorder as described in endocrine disruptive syndromes. Both DDT and $p, p^{\prime}$-DDE have been detected previously at very high concentrations in the mid 1980s, with lower concentrations still being detectable as late as 2001. To establish the effect of DDT and DDE, the vulture estrogen receptor $\alpha(E R \alpha)$ was sequenced from two species using $5^{\prime}$ and $3^{\prime}$ rapid amplification cDNA ends (RACE). Using transient transfected mammalian cell assays, vulture ER $\alpha$ estrogen-dependent transcription activity was validated using various estrogens and DDT derivatives. The receptor assay was sensitive to $p, p^{\prime}$-DDT, $o, p^{\prime}$-DDT and $p, p^{\prime}$-DDE with $\mathrm{EC}_{50}$ of $2.41 \times 10^{-6}, 3.47 \times 10^{-7}$ and $3.81 \times 10^{-5} \mathrm{M}$. When compared to results obtained from human, zebrafish, chicken, salamander and turtle, the vulture ER $\alpha$ showed high sensitivity to $o, p^{\prime}$-DDT and intermediately responsive to $p, p^{\prime}$-DDE. Vulture ER $\alpha$ is, however, not responsive to the DDT and DDE levels reported in the plasma of vultures from the last population survey, indicating that the Southern African vulture are not currently exposed to disruptive levels of these contaminants.
\end{abstract}

(c) 2008 Elsevier Inc. All rights reserved.

\section{Introduction}

From the nine vulture species resident to Southern Africa, seven are currently listed on the IUCN red list (2007) as being endangered, with even the once ubiquitous White-backed vulture (Gyps africanus) now being considered near threatened. The most endangered of the species is still, however, the Cape Griffon vulture (Gyps coprotheres). In addition to being endemic to only Southern Africa, the Cape Griffon is arguably the largest vulture in Africa (Mundy et al., 1992). Unfortunately, despite being very prominent in their environment, the species has steadily declined over the last century with poor fertility, high nestling mortality, African witchcraft, malicious poisonings and pylon/power line injuries being listed as causes (Piper et al., 1981; Komen, 1991; Fernie and Reynolds, 2005; IUCN red list, 2007). Of these, nestling mortalities is probably the most important as estimates in the 1980s placed the survival of first-year nestlings at $17 \%$, with the overall probability of a hatchling reaching three years being 10\% (Piper et al., 1981). This low

\footnotetext{
* Corresponding author. Fax: +27 125298304.

E-mail address: Vinny.naidoo@up.ac.za (V. Naidoo).
}

rearing rate is made more extreme when one considers that sexual maturity is only reached at 5 years with only one egg being produced a year.

With the majority of dead chicks from the above study showing abnormal bone development (osteodystrophy), a deficiency of dietary calcium was believed to be the underlying cause of both the poor hatchability and rearing success seen in the species (Piper et al., 1981). More importantly, this calcium deficiency was directly related to the encroachment of cattle ranches into the vulture foraging areas (Mundy et al., 1992). With cattle ranching requiring the removal of the large carnivores an important symbiotic relationship had become disrupted, as the only source of calcium available to the wild vultures were the crushed bones left behind from large predator feedings. Thus with the adult birds being calcium deficient, the egg and developing fetus were also denied sufficient calcium with the end result being abnormal skeletal development and/or death.

To overcome this problem, the Endangered Wildlife Trust (EWT) of South Africa initiated a system of vulture restaurants where farmers and game hunters were encouraged to place out dead cattle and trophy kills for the feeding of the birds (Mundy et al., 1992; Reynolds et al., 2004). To accommodate 
for the osteodystrophy, farmers were also advised to place out crushed bones. Over the years this feeding system has flourished and still operates smoothly to this day with hundreds of birds, mainly G. africanus, G. coprotheres and Torgos tracheliotus, feeding at over 180 sites around the country in any week (unpublished restaurant survey). However, despite the country-wide success of the vulture restaurant program, the population of G. coprotheres continues to decline with the latest ICUN red list listing the species at only 4000 breeding pairs. More importantly, only ten breeding pairs are believed to be present in Mozambique, none in Namibia and Zimbabwe, with the species already extinct in Swaziland. With the species steadily declining, despite adequately nutritional support, some other underlying mechanism has to be involved with the poor breeding success of the species. With skeletal abnormalities, poor hatchability and increased hatchling mortalities in other species being blamed on estrogenic effects of low doses of the organochlorines (Grünfeld and Bonefeld-Jorgensen, 2004; Kojima et al., 2005), it is plausible that the poor breeding and rearing success in the Cape Griffon is also due to an underlying endocrine disruptive (ED) syndrome (Bitman et al., 1968; Akins and Tuan, 1993; Danzo, 1997; Sonne et al., 2004; Derfoul et al., 2003).

Further support for an ED syndrome in the Cape and other vulture populations comes from their documented history of exposure to fairly high levels of DDT. In one study, DDT was present in the eggs at concentrations up $4 \times 10^{-6} \mathrm{mg} / \mathrm{kg}$ dry weight (Mundy et al., 1982). In more recent studies, DDT and DDE were detectable in tissues at concentrations up to 1.6 to $3.2 \times 10^{-11} \mathrm{M}$ and $10 \mu \mathrm{g} / \mathrm{L}$, respectively (van Wyk et al., 2001a). Even though these concentrations were considered low and non-significant i.e. non-toxic by the authors, we feel that these concentrations could still have an influence on the vulture estrogen receptor (ER) in an endocrine disruptive manner. The latter is important as ERs in vertebrates function as transcription factors that, when stimulated, induced physiological changes in cellular functions via gene expression (Blumberg and Evans, 1998; Hawkins et al., 2000). At present, three different types of ERs have been identified, ER $\alpha, \operatorname{ER} \beta$ and $E R \gamma$, of which the former two have previously been identified in avian species (Krust et al., 1986; Bernard et al., 1999; Lakaye et al., 1998). In addition to being responsive to natural ligands such as estradiol and synthetic estrogens such as diethylstilbestrol, the ERs are also responsive to estrogen-like agrochemicals. The most common of these chemicals are the organochlorines such as DDT and DDE, which are known to be demonstrated innate competitive agonistic activity for ER binding sites (Kojima et al., 2005).

Therefore, to ascertain if DDT and DDE could have an adverse effect on vulture reproduction, we sequenced and cloned the vulture ER $\alpha$ from two vulture species, validated an in vitro ER reporter assay prior to determining the influence of $p, p^{\prime}$-DDT, $o, p^{\prime}$-DDT and $p, p^{\prime}$-DDE on receptor transcription activity. These compounds selected as historical tissue and plasma concentrations were also available for evaluation.

\section{Materials and methods}

\subsection{Chemical reagents}

17 $\beta$-Estradiol ( $E_{2}$, purity: 98\%), diethylstilbestrol (DES, purity: $99 \%)$, estrone ( $E_{1}$, purity: $\left.98 \%\right)$, estriol ( $E_{3}$, purity: $\left.98 \%\right)$ and $17 \alpha-$ ethynylestradiol ( $\mathrm{EE}_{2}$, purity: $98 \%$ ) were from Sigma-Aldrich Corp. (St. Louis, MO, USA). $p, p^{\prime}$-DDT (purity: 99\%), o, $p^{\prime}$-DDT (purity: 99.5\%) and $p, p^{\prime}$-DDE (purity: 99\%) were obtained from Chem Services (West Chester, PA). All chemicals were dissolved in dimethylsulfoxide (DMSO) prior to use. The concentration of DMSO in the culture medium did not exceed $0.1 \%$.

\subsection{Animals}

An adult Lappet Faced ( $T$. tracheliotus), African White-backed (G. africanus) and Cape Griffon (G. corprotheres) vultures were used in the study. The Cape Griffon was obtained from the Onderstepoort Veterinary Research Institute (OVI) following a case of poisoning while the other birds were donated by the Rhino and Lion non-profit organization after rehabilitation efforts had failed. For the latter euthanasia was by sodium pentobarbitone overdose intravenous. Liver samples were harvested by sterile necropsy and stored in RNAlater at $-30^{\circ} \mathrm{C}$.

\subsection{Molecular cloning of estrogen receptor}

Two conserved amino acid regions in the DNA-binding domain (GYHYGVW) and the ligand-binding domain (NKGM/ IEHL) of the ER were selected for degenerated oligonucleotides (primer A: 5-GGNTAYCAYTAYGGNGTNTGG-3 and primer B: 5-ARRTGYTCNATNCCYTTRTT-3). As a template for PCR, the first-strand cDNA was synthesized from $1.0 \mu \mathrm{g}$ of total RNA isolated from liver tissue using SuperScriptIII reverse-transcriptase (Invitrogen, Carlsbad, CA). Primers A and B were used for the first-round PCR, and then the second-round PCR using primer C (CEGCKAF: 5-TGYGARGGNTGYAARGCNTTY-3) and primer B was done. The amplified DNA fragment was subcloned with the TA-cloning plasmid pCR2.1 vector (Invitrogen), sequenced using a BigDye terminator Cycle Sequencing-kit (PE-Biosystems, Foster City, CA) with T7 and M13-reverse primer, and analyzed on the ABI PRISM 377 automatic sequencer (PE-Biosystems). The 5'- and 3'- ends of ER cDNA were amplified by rapid amplification of the cDNA end (RACE) using a SMART RACE cDNA Amplification kit (BD Biosciences Clontech, Palo Alto, CA). A single full-length transcript of the open reading frame was amplified using the primer set at the $5^{\prime}$ untranslated region and $3^{\prime}$ untranslated region, and then PCR products were cloned into TOPO-Blunt vector (Invitrogen) and sequenced from multiple clones, using a majority rule method to correct sequence errors.

\subsection{Database and sequence analysis}

All sequences generated were searched for similarity using Blastn and Blastp on the online server of the National Center of Biotechnology Information. The predicted amino acid sequences for the vulture and the three other reported avian species, domestic chicken (Gallus gallus, X03805), Japanese quail (Coturnix japonica, AF442965) and the zebrafinch (Taeniopygia guttata, NM_001076701) were aligned with Clustal W (Thompson et al., 1994), and compared for homology using BioEdit (Hall, 1999). The domains of the ER were compared to human (Homo sapiens, M12674), mouse (Mus musculus, NM007956), Japanese giant salamander (Andrias japonicus, AB252211), turtle (Pseudemys nelsoni, AB301060) and zebrafish (Danio rerio, AB037185).

\subsection{Construction of plasmid vector}

The full-coding region of vulture, human (GenBank Accession number, M12674), chicken (X03805), turtle (AB301060), Japanese giant salamander (AB252211), zebrafish (AB037185) ERs were amplified by PCR with KOD DNA polymerase (TOYOBO Biochemicals, Osaka, Japan). The PCR products were gel-purified and ligated into pcDNA3.1 vector (Invitrogen). An estrogen-regulated reporter vector containing four estrogen-responsive elements (4XERE), named pGL3-4xERE was constructed as described previously (Katsu et al., 2006). 


\subsection{Transactivation assays}

HEK293 cells were seeded in 24 -well plates at $5 \times 10^{4}$ cells/well in phenol-red free Dulbecco's modified Eagle's medium (Sigma-Aldrich Corp.) supplemented with $10 \%$ charcoal/dextran treated fetal bovine serum (Hyclone, South Logan, UT). After $24 \mathrm{~h}$, the cells were transfected with $400 \mathrm{ng}$ of pGL3-4xERE, $100 \mathrm{ng}$ of pRL-TK (as an internal control to normalize for variation in transfection efficiency; contains the Renilla reniformis luciferase gene with the herpes simplex virus thymidine kinase promoter; Promega), and
400 ng of pcDNA3.1-ER using Fugene 6 transfection reagent (Roche Diagnostics, Basel, Switzerland) according to the manufacturers' instructions. After $1 \mathrm{~h}$ of incubation, cultures were exposed to various concentrations of steroid hormones or chemicals for $48 \mathrm{~h}$ as previously described (Katsu et al., 2006). The cells were collected, and then the luciferase activity of the cells was measured by a chemiluminescence assay with Dual-Luciferase Reporter Assay System (Promega) on a Turner Designs Luminometer TD-20/20 (Promega). Promoter activity was calculated as firefly (Photinus pyralis)-luciferase activity/sea pansy ( $R$. reniformis)-luciferase

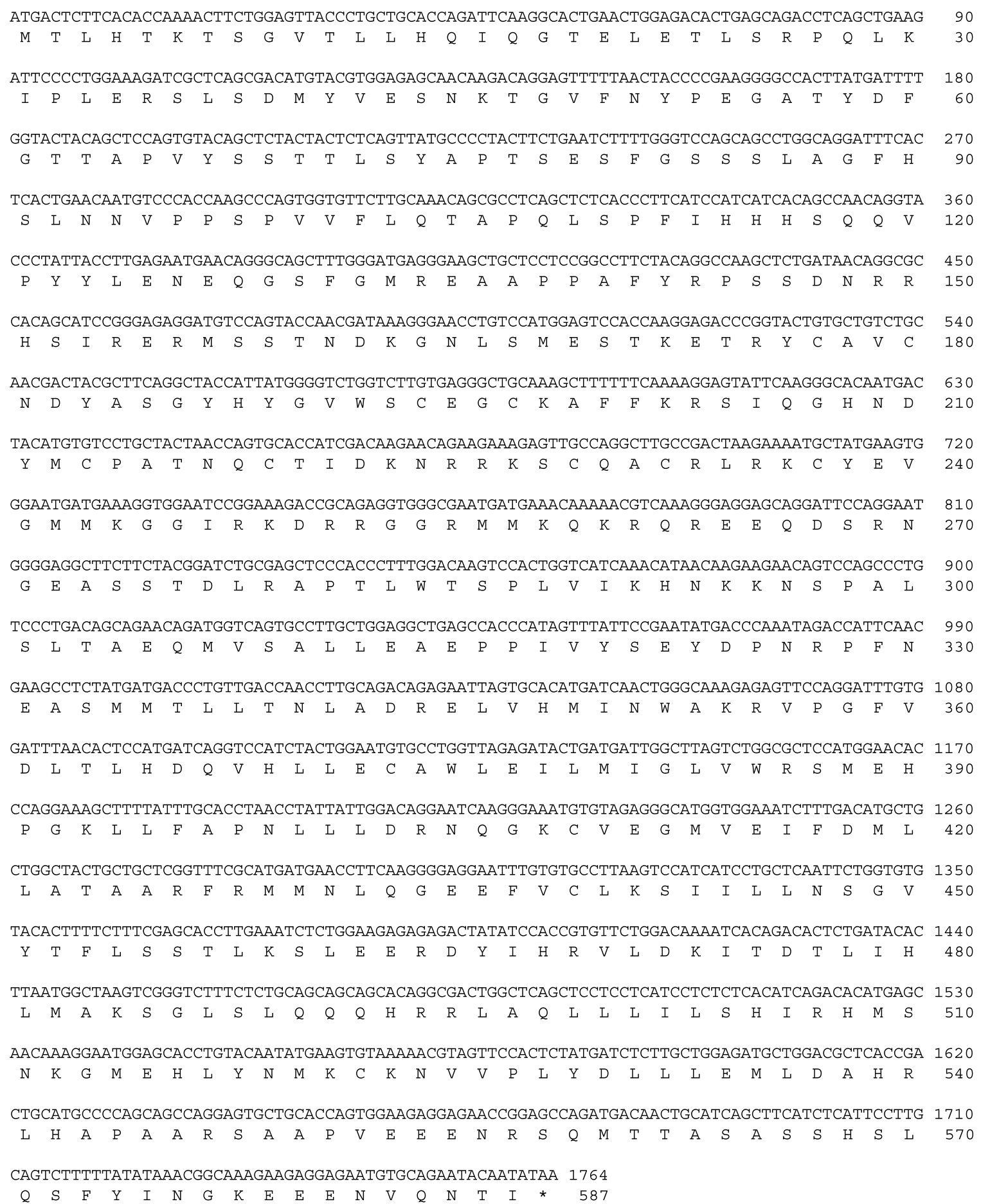

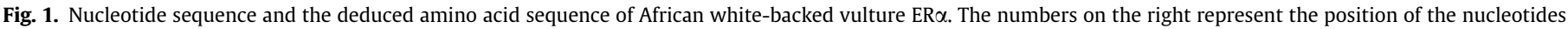
and the amino acids. 
activity. All transfections were performed at least three times, and the values shown are means $\pm \mathrm{SE}$ from the three separate experiments.

\subsection{DDE depletion extrapolations}

The species depletion of DDE was extrapolated from previously reported data over the last 20 years for G. africanus and G. corprotheres (Mundy et al., 1982; van Wyk et al., 1993, 2001a). Egg DDE concentrations were converted to plausible maternal muscle concentrations according to the following equation: $y=18.191 \mathrm{X}+$ 3211, established by Rauschenberger et al. (2002). This extrapolation was based on the pharmacokinetics of DDT and DDE which shows that tissue drug concentration is a factor of perfusion, compartmental lipid content and the lipid solubility of the drug (US Department of Health and Human Services, 2002). Muscle concentrations were converted to an approximate plasma concen- tration using the partition co-efficient of 0.84 established from data presented in van Wyk et al. (2001a).

\subsection{Statistical methods}

Results are presented as means \pm SE (SEM). All multi-group comparisons were performed using ANOVA followed by Bonferroni. Software used was GraphPad Prism (version 4.0c; GraphPad Software, Inc., San Diego, CA). $P<0.05$ was considered statistically significant.

\section{Results}

\subsection{Cloning of vulture $E R \alpha$}

Using standard PCR techniques described above, we obtained the partial DNA fragments of estrogen receptor alpha (ER $\alpha$ ) from

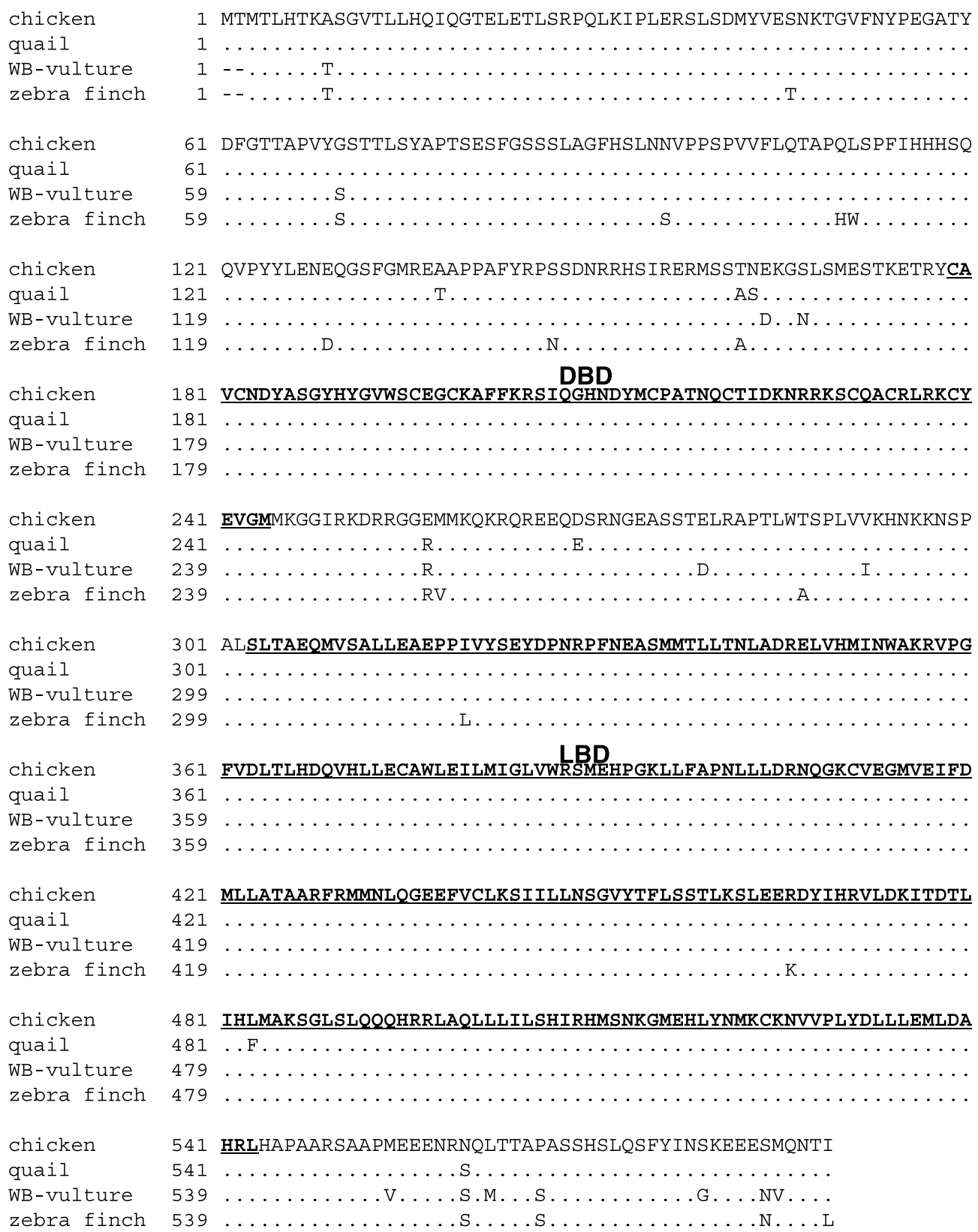

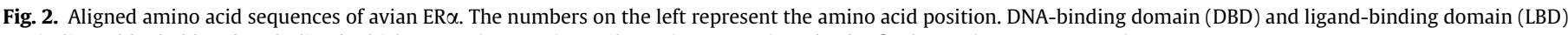
are indicated by bold and underlined. Chicken ER $\alpha$ (X03805); quail ER $\alpha$ (AF442965), and zebrafinch ER $\alpha$ (NM_001076701). 


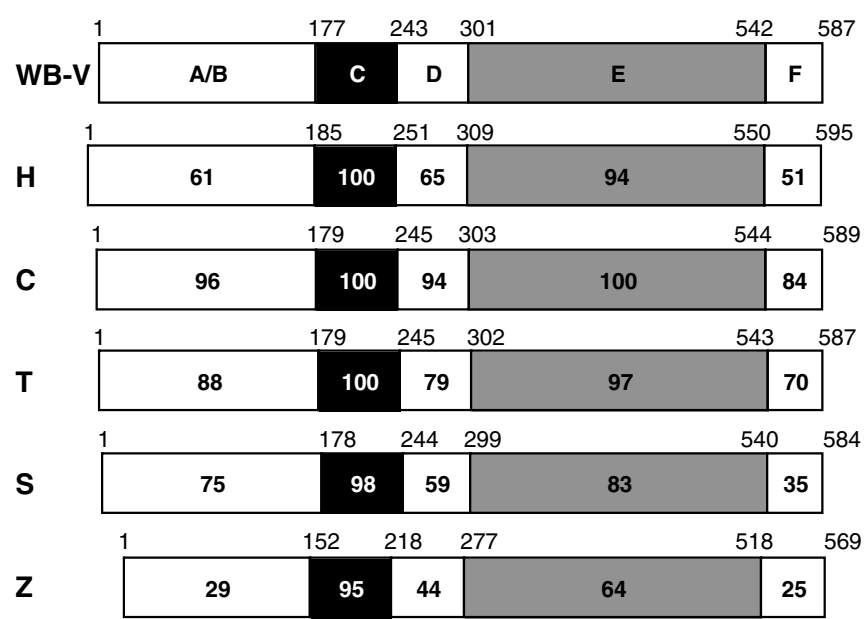

Fig. 3. Comparison of WB-vulture ER $\alpha$ protein with ER $\alpha$ S of several species (WB-V, white-backed vulture; $H$, human; $C$, chicken; $T$, turtle; S, salamander; $Z$, zebrafish; GenBank accession numbers are human ER $\alpha$, M12674; chicken ER $\alpha$, X03805; turtle $\mathrm{ER} \alpha, \mathrm{AB} 301060$; Japanese giant salamander $\mathrm{ER} \alpha, \mathrm{AB} 252211$; and zebrafish ER $\alpha$,

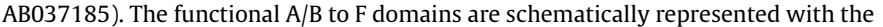
numbers of amino acid residues indicated.

African white-backed vulture (WB-vulture) and Lappet Faced vulture (LF-vulture). Using RACE technique, the full-length clones of WB-vulture and LF-vulture ER $\alpha$ were isolated (Genbank Accession numbers, WB-vulture ER $\alpha$ : AB447536 and LF-vulture ER $\alpha$ : $\mathrm{AB} 447537)$. The deduced protein of WB-vulture ER $\alpha$ is 587 amino acids (aa), calculated molecular weight of $66,524.64 \mathrm{Da}$ (Fig. 1 ). The deduced amino acid sequence of LF-vulture ER $\alpha$ is almost the same, except for valine residue in exchange for alanine one at 565 th in the $\mathrm{F}$ domain, and the eight points differences between WB- and LF-vulture ER $\alpha$ of nucleic acid sequence were detected (data not shown).

The identity of between vulture ER $\alpha$ and avian ER $\alpha$ s that are entered in GenBank were examined. Full-length avian ER $\alpha$ sequence was reported from chicken, Japanese quail and zebrafinch (GenBank accession numbers, X03805, AF442965 and NM_001076701, respectively). The overall identity percentages of WB-vulture ER $\alpha$ were $97 \%$ (chicken ER $\alpha$ ), 96\% (Japanese quail $\mathrm{ER} \alpha$ ), and 96\% (zebrafinch ER $\alpha$ ) (Fig. 2).

Using the nomenclature of Krust et al. (1986), the WB-vulture $\mathrm{ER} \alpha$ sequence can be divided into $\mathrm{A} / \mathrm{B}, \mathrm{C}$ (DNA-binding domain), $D$, E (ligand-binding domain) and $F$ domains based on its sequence identity with other steroid hormone receptors. The vulture $(\mathrm{WB})$ sequence was compared with six other available ER $\alpha$ sequences (human, chicken, turtle, Japanese giant salamander, zebrafish). WB-vulture $E R \alpha$ shared $96-61 \%$ identity in the $A / B$ domain of human, chicken, turtle and Japanese giant salamander (Fig. 3). In contrast, the similarity to zebrafish $E R \alpha$ is

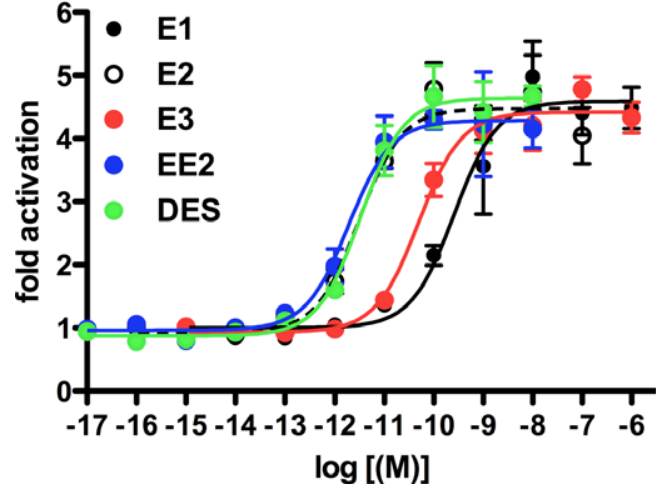

Fig. 4. Transcriptional activities of WB-vulture ER $\alpha$. Dose-response profile of WBvulture ER $\alpha$ activation by estrogens. HEK293 cells were transiently transfected with the ERE-containing vector together with a vulture $\mathrm{ER} \alpha$ expression vector. Cells were incubated with increasing concentrations of $E_{1} / E_{3}\left(10^{-15} \mathrm{M}-10^{-6} \mathrm{M}\right), \mathrm{E}_{2}\left(10^{-16} \mathrm{M}-\right.$ $\left.10^{-7} \mathrm{M}\right)$ and $\mathrm{EE}_{2} / \mathrm{DES}\left(10^{-17} \mathrm{M}-10^{-7} \mathrm{M}\right)$. Each point represents the mean of triplicate determinations, and vertical bars represent the means $\pm \mathrm{SE}$.

significantly lower (29\%). In general, the A/B domains of the fish ERs are different from other vertebrates. When WB-vulture ER $\alpha$ was compared to other domains of common vertebrates, we found a 100-95\% identity in the $\mathrm{C}$ domain (DNA-binding domain), $94-44 \%$ identity in the D domain, and $100-64 \%$ identity in the $\mathrm{E}$ domain (the ligand-binding domain) (Fig. 3). The $\mathrm{F}$ domains in the C-terminal region of ER $\alpha$ are different from each other. Thus, domains C (DNA-binding domain) and E (ligandbinding domain) are highly conserved among all vertebrate ERs studied to date. The overall identities of WB-vulture ER $\alpha$ with human, turtle, Japanese giant salamander or zebrafish ER $\alpha$ were $78 \%, 91 \%, 76 \%$ and $50 \%$, respectively.

\subsection{Transcriptional activity of vulture estrogen receptor}

A transactivation assay was used to determine whether vulture ER $\alpha$ shows an estrogen-dependent transcriptional activity. ERs activate transcription in an estrogen-dependent manner through a variety of response sites, the most typical of which is composed of two head-to-head GGTCA half sites separated by three nucleotides, estrogen-response elements (EREs). To analyze the transcriptional activities of vulture $E R \alpha$, we cotransfected a reporter plasmid containing four EREs in front of a minimal tk promoter driving the luciferase reporter gene (EREtkLuc), together with a vulture ER $\alpha$ encoding plasmid and pRL-TK control plasmid. The vulture ER $\alpha$ activated the expression of luciferase reporter gene in a dose-dependent manner of estrogens (Fig. 4). $\mathrm{EC}_{50}$ values were calculated from the concentration-related responses for the five steroidal estrogens and used for determining their potency (Table 1 ). For vulture $\mathrm{ER} \alpha$, the relative potency of $\mathrm{EE}_{2}$ (160.6\%) was higher, but lower for $\mathrm{E}_{1}(1.2 \%)$ and $\mathrm{E}_{3}(6.1 \%)$ as compared to $\mathrm{E} 2$.

Table 1

Gene transcription activity of WB ER $\alpha$ following $48 \mathrm{~h}$ of incubation with various estrogens, DDT and DDE

\begin{tabular}{|c|c|c|c|c|}
\hline Drug & $\mathrm{EC} 50(\mathrm{M})$ & $95 \% \mathrm{CI}(\mathrm{M})$ & $\mathrm{RP}(\%)$ & NOEL \\
\hline$E_{2}$ & $3.035 \times 10^{-12}$ & $1.45 \times 10^{-12}$ to $6.36 \times 10^{-12}$ & 100 & $1 \times 10^{-13}$ \\
\hline$E_{1}$ & $2.576 \times 10^{-10}$ & $1.12 \times 10^{-10}$ to $5.91 \times 10^{-10}$ & 1.17 & $1 \times 10^{-13}$ \\
\hline$E_{3}$ & $4.958 \times 10^{-11}$ & $2.91 \times 10^{-11}$ to $8.44 \times 10^{-11}$ & 6.12 & $1 \times 10^{-13}$ \\
\hline $\mathrm{EE}_{2}$ & $1.890 \times 10^{-12}$ & $8.70 \times 10^{-13}$ to $4.10 \times 10^{-12}$ & 160.58 & $1 \times 10^{-14}$ \\
\hline DES & $3.314 \times 10^{-12}$ & $1.87 \times 10^{-12}$ to $5.88 \times 10^{-12}$ & 91.58 & $1 \times 10^{-16}$ \\
\hline$p, p^{\prime}-\mathrm{DDT}$ & $2.41 \times 10^{-6}$ & $1.16 \times 10^{-6}$ to $5.01 \times 10^{-6}$ & 1. $\times 10^{-4}$ & $1 \times 10^{-9}$ \\
\hline$o, p^{\prime}-\mathrm{DDT}$ & $3.47 \times 10^{-7}$ & $2.46 \times 10^{-7}$ to $4.89 \times 10^{-7}$ & 1. $\times 10^{-3}$ & $1 \times 10^{-9}$ \\
\hline$p, p^{\prime}-\mathrm{DDE}$ & $3.81 \times 10^{-5}$ & $3.24 \times 10^{-7}$ to $4.47 \times 10^{-3}$ & 9. $\times 10^{-6}$ & $1 \times 10^{-9}$ \\
\hline
\end{tabular}

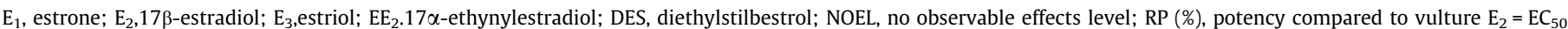
vulture $17 \beta$-estradiol/ $\mathrm{EC}_{50}$ chemical $\times 100 ; 95 \% \mathrm{CI}$, represents the upper and lower confidence interval of the EC50 obtained from each assay. 
Table 2

$\mathrm{EC}_{50}$ values determined in different species for DDT/DDE and their potency compared to $17 \beta$-estradiol

\begin{tabular}{|c|c|c|c|c|}
\hline \multirow[t]{2}{*}{ Species } & \multicolumn{4}{|l|}{ Chemicals } \\
\hline & $E_{2}$ & $p, p^{\prime}$-DDT & $o, p^{\prime}$-DDT & $p, p^{\prime}-\mathrm{DDE}$ \\
\hline Vulture & $3.32 \times 10^{-12}(100)$ & $2.41 \times 10^{-6}\left(1.38 \times 10^{-4}\right)$ & $3.47 \times 10^{-7}\left(9.58 \times 10^{-4}\right)$ & $3.81 \times 10^{-5}\left(8.73 \times 10^{-6}\right)$ \\
\hline Salamander & $1.67 \times 10^{-10}(100)$ & $3.89 \times 10^{-5}\left(4.30 \times 10^{-4}\right)$ & $1.98 \times 10^{-6}\left(8.45 \times 10^{-3}\right)$ & $2.13 \times 10^{-5}\left(7.87 \times 10^{-4}\right)$ \\
\hline Turtle & $6.82 \times 10^{-12}(100)$ & $3.31 \times 10^{-5}\left(2.06 \times 10^{-5}\right)$ & $3.71 \times 10^{-7}\left(1.84 \times 10^{-3}\right)$ & $9.50 \times 10^{-5}\left(7.18 \times 10^{-6}\right)$ \\
\hline Human & $1.51 \times 10^{-12}(100)$ & $1.33 \times 10^{-5}\left(1.13 \times 10^{-5}\right)$ & $1.25 \times 10^{-7}\left(1.21 \times 10^{-3}\right)$ & $6.97 \times 10^{-5}\left(2.17 \times 10^{-6}\right)$ \\
\hline Chicken & $4.05 \times 10^{-12}(100)$ & $7.09 \times 10^{-6}\left(5.71 \times 10^{-5}\right)$ & $2.90 \times 10^{-7}\left(1.40 \times 10^{-3}\right)$ & $7.11 \times 10^{-5}\left(5.70 \times 10^{-6}\right)$ \\
\hline Zebrafish & $1.62 \times 10^{-10}(100)$ & $2.17 \times 10^{-2}\left(7.48 \times 10^{-7}\right)$ & $2.41 \times 10^{-5}\left(6.75 \times 10^{-4}\right)$ & $2.23 \times 10^{-5}\left(7.27 \times 10^{-4}\right)$ \\
\hline
\end{tabular}

Figures in parenthesis, \% potency compared to species $\mathrm{E}_{2}=\mathrm{EC}_{50}$ species $17 \beta$-estradiol $/ \mathrm{EC}_{50}$ chemical $\times$ response reported for the species $\times 100$.

A

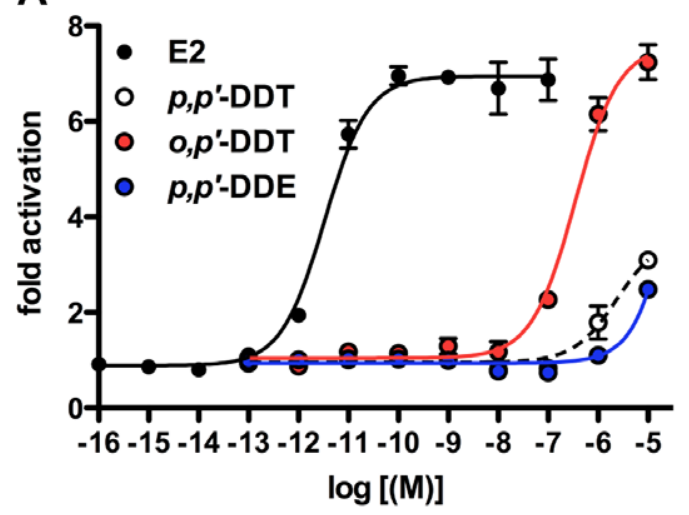

C

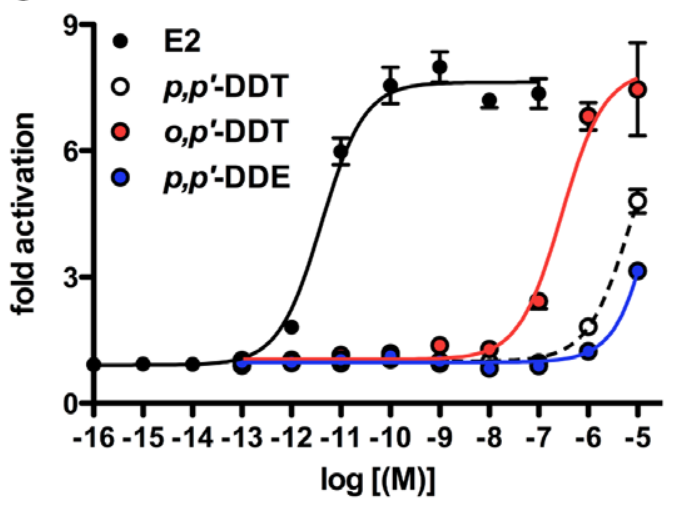

E

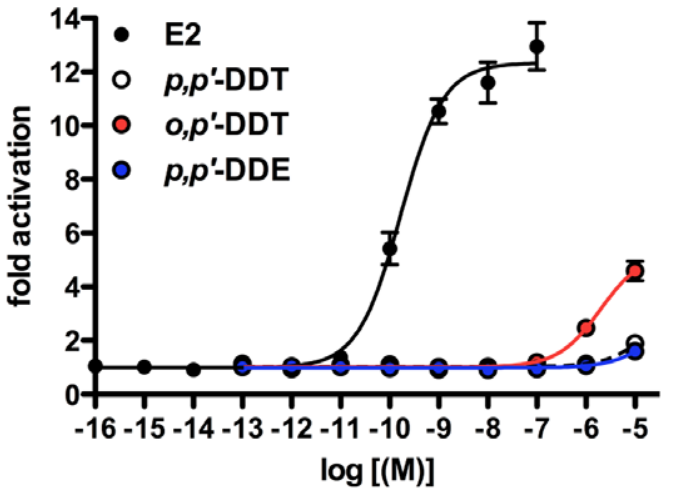

B

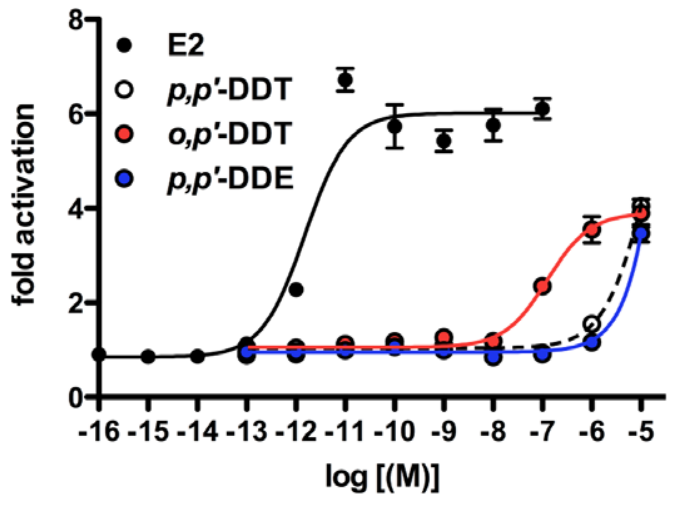

D

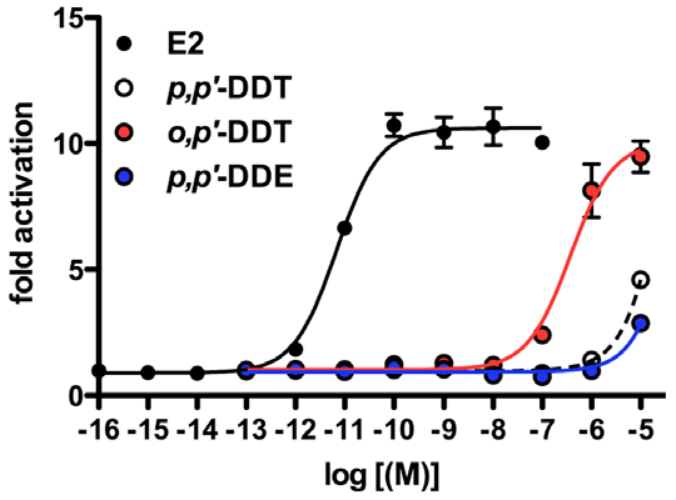

$\mathbf{F}$

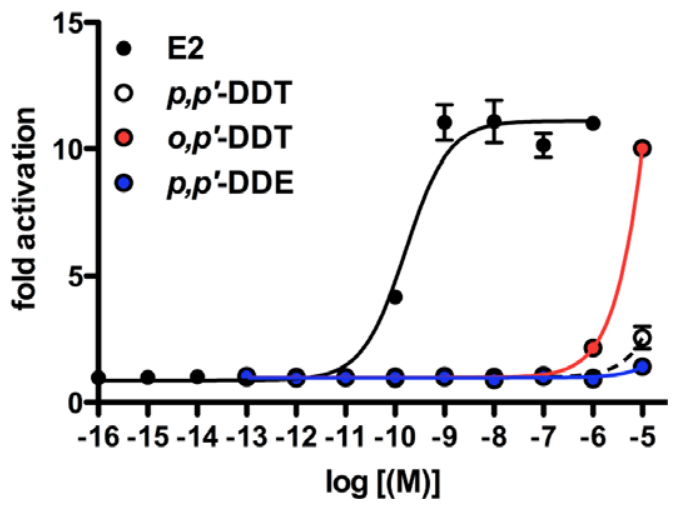

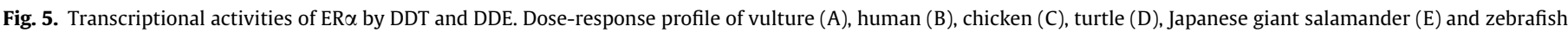

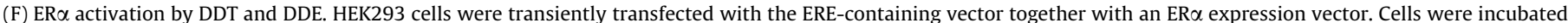

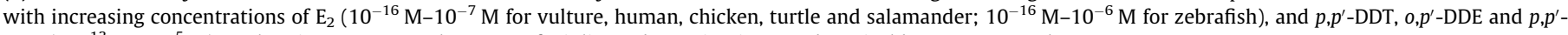
$\mathrm{DDE}\left(10^{-13} \mathrm{M}-10^{-5} \mathrm{M}\right)$. Each point represents the mean of triplicate determinations, and vertical bars represent the means \pm SE. 


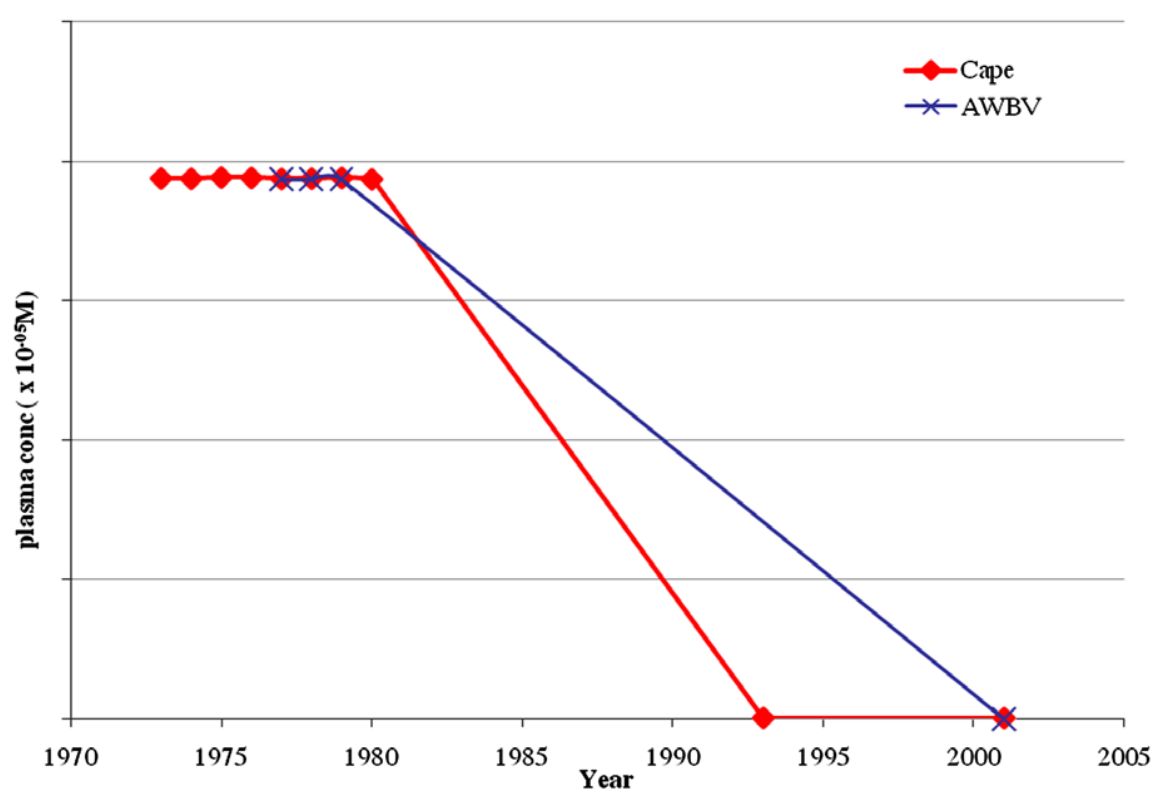

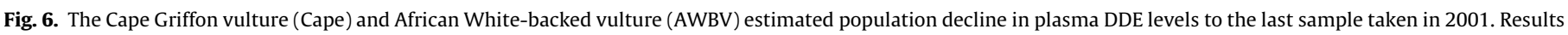
are extrapolated from mean data of Mundy et al., 1982; van Wyk et al., 1993, 2001.

Next, we examined whether vulture ER $\alpha$ is activated by DDT and DDE (Table 1). We used ER $\alpha$ from six animal species, vulture (avian), human (mammalian), chicken (avian), turtle (reptile), Japanese giant salamander (amphibian) and zebrafish (fish) as comparison (Table 2). The vulture, chicken and turtle ER $\alpha$ s were activated by DDT and DDE with the same pattern. Activations of these ER $\alpha$ s were detected at $10^{-7} \mathrm{M} o, p^{\prime}$-DDT, and the maximal level of ER $\alpha$ activity by $o, p^{\prime}$-DDT was reached at the $10^{-5} \mathrm{M}$. The ER $\alpha$ activities by $p, p^{\prime}$-DDT and $p, p^{\prime}$-DDE were detected at $10^{-5} \mathrm{M}$ (Fig. 5A, C and D). The other, human ER $\alpha$ was also activated by $p, p^{\prime}$-DDT, $o, p^{\prime}$-DDT and $p, p^{\prime}$-DDE, however, o, $p^{\prime}$-DDT-induced human ER $\alpha$ activity was not reached at the maximal level of the activity by $\mathrm{E}_{2}$ (Fig. 5B). Zebrafish $\mathrm{ER} \alpha$ is not activated at $10^{-7} \mathrm{M}$ $o, p^{\prime}$-DDT, but its activity was reached at the maximal level at 10 ${ }^{-5} \mathrm{M} o, p^{\prime}$-DDT (Fig. 5F). Japanese giant salamander ER $\alpha$ is activated by $0, p^{\prime}$-DDT, however, its activity is low, and $p, p^{\prime}$-DDT and $p, p^{\prime}$-DDE did not induce the salamander ER $\alpha$ activity (Fig. 5E). These results suggest that avian and reptile ER $\alpha$ s are more sensitive to $o, p^{\prime}$-DDT than other species ERas.

\section{Discussion}

The aim of this study was to determine if the plasma concentrations of DDT and DDE in the Cape and African and White-backed vultures (AWBV) could have adversely influence the endocrine systems. To this end, the ER $\alpha$ was cloned from two vulture species. Although attempts were made, we were unable to clone the ER $\alpha$ from the threatened Cape Griffon vulture (CGV). We are, however, confident that the results obtained from the in vitro assay would be predictive for the CGV as the sequences were essentially identical for the two other vulture species. Further support for using the results of the AWBV comes from van Wyk et al. (2001b), who showed high phylogenetic conservation between the AWBV and CGV. The results are also considered physiologically representative as the maximum response to $E_{2}$ was evident at a concentration of $1 \times 10^{-10} \mathrm{M}$, which is lower than the maximum levels of $1 \times 10$ $-12 \mathrm{M}$ reported in other in avians during normal reproduction (Johnson and van Tienhoven, 1980).

From the results, it is evident that the vulture ER $\alpha$ is more sensitive to the influence of $p, p^{\prime}$-DDT and $p, p^{\prime}$-DDE in comparison to the other animal species tested (Table 2). Although this sensitivity is likely related to the general sensitivity of avians to the organochlorines, the chicken assay was slightly less sensitive. If the species tested could be used as an indicator of familial sensitivity to $p, p^{\prime}$-DDT, in increasing sensitivity would be fish, amphibians, reptiles, and lastly birds. Interestingly, this sensitivity is different for $p, p^{\prime}$-DDE as the order is reptiles, galliformes, human, raptors, fish and amphibians. The significance of the species difference evident cannot be explained at this stage. It does, however, indicate the importance of species differences when evaluating the ER response to the organochlorines.

When the results obtained are compared to published values for $o, p^{\prime}$-DDT and $E_{2}$, the response seen for human was similar, while the zebrafish $o, p^{\prime}$-DDT assay was approximately 13 -fold less sensitive despite a comparative response to $E_{2}$ (Legler et al., 2002). In contrast, the assay was more sensitive than that reported by Gordon et al. (2004), using human ER $\alpha$ for $E_{2}$ but correspondingly ten-fold less sensitive for $p, p^{\prime}$-DDT and $p, p^{\prime}$-DDE. While the differences in response are unknown, it may be due to the difference in the cell types used, as the current assays makes use of human kidney epithelium cells while both the published assays made use of carcinogenic cell lines.

The sensitivity of vulture assay to the organochlorines does explain the poor reproductive success of the species over the last twenty years, as the organochlorines interfere with fertility, egg hatchability, chick survival and bone development. One problem with the assays is their static nature which fails to consider the pharmacokinetics of the molecule in vivo. To allow for this comparison, the in vitro results were matched with the plasma concentrations using simple Pharmacokinetic-Pharmacodynamic modeling. Using the 10 yearly DDE concentrations in various vultures sampled, the population half-life of plasma excretion in the AWBV and CGV was 3.12 and 3.88 years, respectively. When the no effect levels from the reporter gene assay (Table 1) of the DDE is related to the extrapolated depletion curve, it would appear that AWBV and CGV were only free of the estrogenic effects of DDE by mid 1990s (Fig. 6).

\section{Conclusion}

In conclusion, we cloned and sequenced the AWBV and LFV $\mathrm{ER} \alpha$. This is the first report of the full-sequence and in vitro transcriptional activity for the vulture ER. In addition to being the first 
avian ER luciferase assay, it is also the first study to relate the pharmacokinetic pharmacodynamic interaction of DDT and DDE concentration in an endangered species at known plasma concentrations. More importantly, using the in vitro assay, we were able to demonstrate that the vulture ER is sensitive to DDT and DDE. Although these data will not be able to explain the poor reproductive success of the species in the 20th century, the absence of chemicals at effective concentrations from the 2001 would indicate that other factors also play a role in the current constant decline in vulture numbers.

\section{Acknowledgments}

This study was partially funded by the National Research Foundation of South Africa (V.N.), Grants-in-Aid for Scientific Research from the Ministry of Education, Culture, Sports, Science and Technology, Japan (Y. K. and T. I.), and grants from the Ministry of Environment, Japan (Y. K. and T. I.)

\section{References}

Akins, R.E., Tuan, R.S., 1993. Transepithelial calcium transport in the chick chorioallantoic membrane I. Isolation and characterization of chorionic ectoderm cells.. J. Cell Sci. 105, 369-379.

Bernard, D.J., Bentley, G.E., Balthazart, J., Turek, F.W., Ball, G.F., 1999. Androgen receptor, estrogen receptor $\alpha$, and estrogen receptor $\beta$ show distinct patterns of expression in forebrain song control nuclei of european starlings. Endocrinology 140, 4633-4643.

Bitman, J., Cecil, H.C., Harris, S.J., Fries, G.F., 1968. Estrogenic activity of o,p-DDT in the mammalian uterus and avian oviduct. Science 162, 371-372.

Blumberg, B., Evans, R.M., 1998. Orphan nuclear receptors-new ligands and new possibilities. Genes Dev. 12, 3149-3315.

Danzo, B.J., 1997. Environmental xenobiotics may disrupt normal endocrine function by interfering with the binding of physiological ligands to steroid receptors and binding proteins. Environ. Health Perspect. 105, 294-301.

Derfoul, A., Lin, F.J., Awumey, E.M., Kolodzeski, T., Hall, D.J., Tuan, R.S., 2003. Estrogenic endocrine disruptive components interfere with calcium handling and differentiation of human trophoblast cells. J. Cell. Biochem. 89, 755-770.

Fernie, K.J., Reynolds, S.J., 2005. The effects of electromagnetic fields from power lines on avian reproductive biology and physiology: a review. J. Toxicol. Environ. Health 8, 127-140.

Gordon, J.D., Chu, A.C., Chu, M.D., Denison, M.S., Clark, G.C., 2004. Detection of estrogen receptor endocrine disruptor potency of commonly used organochlorine pesticides using the LUMI-CELLä bioassay. Dioxin 66, 169-174.

Grünfeld, H.T., Bonefeld-Jorgensen, E.C., 2004. Effect of in vitro estrogenic pesticides on human oestrogen receptor $\alpha$ and $\beta$ mRNA levels. Toxicol. Lett. 151, 467-480.

Hall, T.A., 1999. Bioedit: a user-friendly biological sequence alignment editor and analysis program for Windows 95/98/NT. Nucleic Acids Symp. 41, 95-98.

Hawkins, M.B., Thornton, J.W., Crews, D., Skipper, J.K., Dotte, A., Thomas, P., 2000. Identification of a third estrogen receptor and reclassification of estrogen receptors in teleosts. Proc. Natl. Acad. Sci. USA 97, 10751-10756.

IUCN Red list of Endangered Species, 2007. Gyps corprotheres, Available online: http://www.iucnredlist.org/earch/details.php/9588/all.
Johnson, A.L., van Tienhoven, T., 1980. Plasma concentrations of six steroids and LH during the ovulatory cycle of the hen, Gallus domesticus. Biol. Reprod. 23, 386393.

Katsu, Y., Kohno, S., Okad, T., Mitsui, N., Tooi, O., Santo, N., Urushitani, H., Fukumotoe, Y., Kuwabara, K., Ashikaga, K., Minamie, S., Kato, S., Ohta, Y., Guillette Jr., L.J., Iguchi, T., 2006. Molecular cloning of estrogen receptor alpha (ER $\alpha$; ESR1) of the Japanese Giant Salamander, Andrias japonicus. Mol. Cell. Endocrinol. 257-258, 84-94.

Kojima, M., Fukunage, K., Sasaki, M., Nakamura, M., Tsuji, M., Ishiyama, T., 2005. Evaluation of estrogenic activities of pesticides using an in vitro reporter gene assay. Int. J. Environ. Health Res. 15, 271-280.

Komen, J., 1991. Energy requirements of nestling cape vultures. Condor 93, 153158.

Krust, A., Green, S., Argos, P., Kumar, V., Walter, P., Bornert, J.M., Chambon, P., 1986. The chicken oestrogen receptor sequence. homology with v-erbA and the human oestrogen and glucocorticoid receptors. EMBO J. 5, 891897.

Lakaye, B., Foidart, A.A., Grisar, T., Balthazart, J., 1998. Partial cloning and distribution of estrogen receptor beta in the avian brain. J. Mol. Neurosci. 9, 2743-2748.

Legler, J., Zeinstra, L., Schuitemaker, F., Lanser, P.H., Bogerd, J., Brouwer, A., Vethaak, A.D., De Voogt, P., Murk, A.J., Van der Berg, B., 2002. Comparison of in vivo and in vitro reporter gene assays for short-term screening of estrogenic activity. Environ. Sci. Technol. 36, 4410-4415.

Mundy, P., Butchart, D., Ledgar, J., Piper, S., 1992. The Vultures of Africa. Acorn Books CC, South Africa.

Mundy, P.J., Grant, K.I., Tannock, J., Wessels, C.L., 1982. Pesticide residues and eggshell thickness of Griffon vulture eggs in southern Africa. J.Wildlife Manag. $46,769-773$.

Piper, S.E., Mundy, P.J., Ledger, J.A., 1981. Estimates of survival in the Cape Vulture, Gyps coprotheres. J. Anim. Ecol. 50, 815-825.

Rauschenberger, R.H., Sepúlveda, M.S., Wiebe, J.J., Ruessler, D.S., Wieser, C.M., Gross, T.S., 2002. Predicting contaminant body burdens from eggs and evidence of maternal transfer in alligator mississippiensis. Presented at the Society for Environmental Toxicology and Chemistry 23rd Annual Meeting, Salt Lake City UT, November 16-20, 2002.

Reynolds, S.J., Mand, R., Tilgar, V., 2004. Calcium supplementation of breeding birds: directions for future research. Ibis 146, 601-614.

Sonne, C., Dietz, R., Born, E.W., Riget, F.F., Kirkegaard, M., Hyldstrup, L., Letcher, R.J., Muir, D.C.G., 2004. Is bone mineral composition disrupted by organochlorines in east greenland polar bears (Ursus maritimus)? Environ. Health Perspect. 112 1711-1716.

Thompson, J.D., Higgins, D.G., Gibson, T.J., 1994. CLUSTAL W: improving the sensitivity of progressive multiple sequence alignment through sequence weighting, position specific gap penalties and weight matrix choice. Nucleic Acids Res. 22, 4673-4680.

US Department of Health and Human Services, 2002. Toxicological profiles for DDT, DDE, and DDD, 1600 Clifton Road NE, E-29 Atlanta, Georgia 30333.

van Wyk, E., Bouwman, H., van der Bank, H., Verdoorn, G.H., Hofmann, D., 2001a. Persistent organochlorine pesticides detected in blood and tissue samples of vultures from different localities in South Africa. Comp. Biochem. Physiol. Part C $129,243-264$.

van Wyk, E., van der Bank, F.H., Verdoorn, G.H., Bouwman, H., 1993. Chlorinated hydrocarbon insecticide residues in the cape griffon vulture (Gyps coprotheres). Comp. Biochem. Physiol. Part C 104, 209-220.

van Wyk, E., van der Banka, H., Verdoorn, G.H., 2001b. Allozyme variation in four populations of African whitebacked vultures (Gyps africanus) and phylogenetic relationships between four vulture species from southern Africa. Biochem. Systemat. Ecol. 29, 485-512. 